\title{
Boundary Conditions of Options: A Demonstration Based on the Stochastic Discount
}

\section{Salvador Cruz Rambaud}

\author{
Departamento de Economía y Empresa, University of Almería \\ Ctra. Sacramento, 04120. La Cañada de San Urbano, Almería. Spain \\ Ana María Sánchez Pérez \\ Departamento de Economía y Empresa, University of Almería \\ Ctra. Sacramento, 04120. La Cañada de San Urbano, Almería. Spain
}

\author{
Doi:10.5901/mjss.2017.v8n1p46
}

\section{Abstract}

The aim of this paper is to provide a proof of the generally accepted boundary conditions of (call and put) financial options from a novel point of view. To do this, we will use an auxiliary discounting function which will be defined in this work. However, the financial options are derivative instruments whose function is risk hedging in contexts of uncertainty, whereby the employed discount function will be necessarily stochastic. More specifically, we will apply the classic properties of the magnitude "discount" to the so-defined discount function to obtain, in a natural way, the noteworthy boundary conditions of financial options. It is well-known that financial options (belonging to the field of stochastic finance) have been studied without any relation with the magnitude "discount" (more characteristic of the classic Financial Mathematics). Consequently, the principal contribution of this work is the construction of a stochastic discount function as a bridge connecting its associated discount and the financial options, being demonstrated that their properties can be mutually derived.

Keywords: Finance, boundary conditions, call option, put option, stochastic discount function.

\section{Introduction}

Financial options are derivative products constructed from a wide variety of assets. These assets of reference, known as underlying assets, can refer to goods, to financial assets (shares or bonds) or to indexes (interest rates, exchange rates or stock market indices). Usually, the risks generated by the underlying assets can be replaced by derivative products, such as futures, options, forwards and swaps.

The option holder has the right to purchase or sell a financial asset in the future at a certain price (Díez de Castro and Macareñas, 1994). The purchase or sale price guaranteed by the option at maturity, $T$, is called the strike price, which we will represent with the letter $E$ (Devolder, 1997).

The fundamental criterion to classify a financial option is according to the kind of right that it guarantees. Thus, if the price per share of the common stock is $S$ at time 0 :

- Holding a call option guarantees the right to purchase, at instant $T$, an asset at price $E$ agreed at instant 0 .

- Holding a put option guarantees the right to sell an asset at the specific price $E$, set at instant 0 .

The holder will exercise the option only if this improves the chances of obtaining a profitability with respect to the market price of the underlying asset at instant $T$. Said in other words, it eliminates the risk of obtaining negative profitabilities. More specifically, the possible losses are limited to a fixed amount, the call (or put) price, whereas the potential benefits are unlimited, depending on the underlying asset price evolution.

This paper will deal with the proof of some basic boundary conditions for call and put options. Usually the used arguments to demonstrate these boundary conditions are based on arbitrage which means that investors prefer more wealth to less (Merton, 1973 and Liu et al., 2015). Nevertheless, if some additional assumptions are required to investor 
preferences, more accurate bounds on option prices can be derived (Perrakis and Ryan, 1984; Ritchken, 1985; Ritchken and Kuo, 1988; Levy, 1985; Oancea and Perrakis, 2014 and Jahnke et al., 2015). Jarrow and Rudd (1983) analyzed the bounds in case of uncertain dividends and random interest rates, and Cox and Rubinstein also provide a rigorous treatment of this subject. Finally, empirical and theoretical tests of these bounds were discussed by Gould and Galai (1974), Galai (1978), Vorst, (1990), Klemkosky and Resnick (1979), Stoll (1969), Kalay et al. (2014) and Chua et al. (2015) (for a survey, see Galai (1983)). Others authors like Björk, (2009), Björk and Slinko (2006), Cochrane (2009), Murgoci, (2013) and Hong (2013) study the asset pricing by the correlation of the discount factor with the payoff in case of arbitrage.

The approach of this paper is different because, starting from the idea of hedging shown in the concept of option, we will construct a stochastic discount function whose properties will allow us to deduce the basic boundary conditions of both call and put options. In effect, we will use the "friendly" properties of the magnitude "discount" to derive the required boundary conditions of options. The main contribution of this methodology is that the properties of the discount function are well-known and easily understood by investor.

The organization of this paper is as follows. The basic boundary conditions of options are analyzed in Section 2, while the usual properties of the financial discount are shown in Section 3. Later, Section 4 introduces the justification of the boundary conditions of call and put options starting from the generally accepted properties of financial discount. To do this, the possible definitions of an auxiliary stochastic discount function are discussed, with the aim of introducing in its calculation the expressions of a call or a put option. Finally, Section 5 summarizes and concludes.

\section{Boundary Conditions of Call and Put Options}

In order to enunciate the general call and put boundary conditions, it is necessary to establish a series of previous ideal assumptions (Black and Scholes, 1973) required to guarantee that the arbitrage works conveniently:

- There is no arbitrage opportunity.

- The stock does not pay a dividend.

- It is possible to borrow and lend any amount, even fractional, of cash at the risk-free rate.

- It is possible to buy and sell any amount, even fractional, of the stock (which includes short selling).

- The above transactions do not incur any fees or costs (i.e., frictionless market).

\subsection{Boundary conditions of a call option.}

In this subsection we are going to present the boundary conditions of the price, $C$, of a call option taking into account the hypotheses aforementioned in last paragraph. These conditions provide us some upper and lower bounds for an option price. It is well-known that the price of a call option is a function of $S, E$, and $T$ :

$C=C(S, E, T)$.

Nevertheless, for the sake of simplicity, we will simply denote this price with $C$.

$\mathrm{C}_{1}$. The price a call option must be greater than 0 :

$C \geq 0$.

Therefore, 0 is the lower limit of the option price.

$C_{2}$. The price of a call option must be greater than the difference between the underlying asset price at time $0, S$, and the present value of the strike price, $E(1+i)^{-T}$ :

$$
C \geq S-E(1+i)^{-T},
$$

where $i$ the risk-free interest rate and $T$ the period until the option maturity.

$\mathbf{C}_{3}$. The price of a call option must be lesser than the underlying asset value at time 0 , which becomes the upper bound of the option price:

$$
\frac{\frac{\partial D_{T}(E)}{\partial T}}{D(E)}>\ln (1+i) .
$$

$C_{4}$. The price of a call option is inversely related to its strike price, $E$. In other words:

if $E_{1} \leq E_{2}$, then $C_{1} \geq C_{2}$.

$C_{5}$. Based on boundary condition $\mathbf{C}_{4}$ and assuming that $E_{1}<E_{2}$, the following inequality holds: 
$\left(E_{2}-E_{1}\right)(1+i)^{-T} \geq C_{1}-C_{2}$.

$C_{6}$. The price of a call option increases as maturity increases:

$C_{1} \leq C_{2}$, if $T_{1}<T_{2}$.

$\mathbf{C}_{7}$. The price of a call option follows a convex function with respect to the strike price. Thus, if the strike price of a call option is intermediate between other two ones:

$E_{1}<E_{2}<E_{3}$,

then the price of the corresponding call option must be lesser than the weighted average price of the other two options, $C_{1}$ and $C_{3}$, in the following way:

$$
C_{2} \leq C_{1} \frac{E_{3}-E_{2}}{E_{3}-E_{1}}+C_{3} \frac{E_{2}-E_{1}}{E_{3}-E_{1}} \text {. }
$$

\subsection{Boundary conditions for put options.}

Analogously to call options, the price of a put option, $P$, satisfies a set of boundary conditions which will be more briefly presented:

P1. $P \geq 0$

P2. $P \geq E(1+i)^{-T}-S$.

$P_{3}$. The put price has to be lower than the present value of the strike price:

$P \leq E(1+i)^{-T}$.

Thus, the bounds of a put option price are:

$\max \left(0, E(1+i)^{-T}-S\right) \leq P \leq E(1+i)$.

P4. $P_{1} \leq P_{2}$, whenever $E_{1}<E_{2}$, that is, the price of a put option is increasing with the strike price, contrarily to the price of a call option.

P5. $\left(E_{2}-E_{1}\right)(1+i)^{-T} \geq P_{2}-P_{1}$, being $E_{2}>E_{1}$.

$P_{6} . P_{1} \leq P_{2}$, if $T_{1}<T_{2}$, i.e., the option price increases, as maturity increases.

P. $P_{2} \leq \frac{E_{3}-E_{2}}{E_{3}-E_{1}} P_{1}+\frac{E_{2}-E_{1}}{E_{3}-E_{1}} P_{3}$, being $E_{1}<E_{2}<E_{3}$.

Not fulfilling these conditions, by either the call option or the put option, would lead, automatically, in arbitrage by investors. So, they will seize opportunities to make money without risk, as soon as possible, leading to rapid adjustment that restores the aforementioned inequalities.

\section{Financial Discount Properties}

A discount function is the analytical expression used to obtain the value of a given amount $E$, available at time $T$, at a previous moment denoted by 0 (González Català 1992).

It is well known that, in order to obtain the discount magnitude, $D(E)$, we have to subtract the discounted value, $E(1+i)^{-T}$, from the future amount, $E$. For instance, using the exponential discounting:

$D(E)=E-E(1+i)^{-T}$.

Graphically we have:

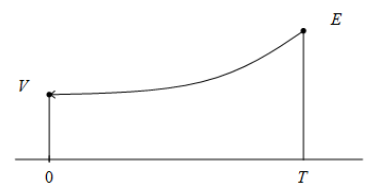

Fig1: A discount function.

In order to represent a rational trade-off of amounts, the discount must satisfy a set of basic properties:

$D_{1}$. The discount must be positive: 
$D(E)>0$.

$D_{2}$. The discount must be lower than the amount to be discounted:

$D(E)<E$.

$D_{3}$. The discount must to be increasing with respect to the discounted amount:

$D\left(E_{1}\right)<D\left(E_{2}\right)$,

if $E_{1}<E_{2}$.

$D_{4}$. The discount function must decreasing with respect to the time, so the discount must be increasing with respect to this variable:

$D\left(E_{1}\right)<D\left(E_{2}\right)$,

if $T_{1}<T_{2}$.

$D_{5}$. The discount is a convex function of the amount to be discounted, i.e., the discount increases more than proportionately with respect to the initial amount:

$$
\frac{D\left(E_{2}\right)-D\left(E_{1}\right)}{E_{2}-E_{1}}<\frac{D\left(E_{3}\right)-D\left(E_{2}\right)}{E_{3}-E_{2}},
$$

being $E_{1}<E_{2}<E_{3}$.

\section{A Derivation of Call and Put Options from the Discount Properties}

In Cruz and Trinidad (2004), the relationship between the boundary conditions of the price of call and put options, and the discount magnitude is analyzed, being argued that the price of a call option, $C$, might be interpreted as a discount magnitude. On the other hand, in Kunsch (2008), we can find a methodology to determine a suitable discount rate using option pricing in the context of environmental management.

Based on the results obtained in Cruz and Trinidad (2004), we will analyze the different ways to determine the discount magnitude corresponding to a suitable stochastic discount function in whose definition the expressions of the price of either a call or a put option takes parts. This way, starting from the properties of the so-defined discount function, we will be ale to derive the boundary conditions of the price of both a call and a put option.

To do this, we are going to firstly propose the following expression of a stochastic discount function (Cruz, Valls and García, 2002):

$$
F(E)=E \int_{E}^{+\infty} f(x) \mathrm{d} x+\int_{0}^{E} x f(x) \mathrm{d} x,
$$

where $f$ is the density function of $X(T)$, the random amount at time $T$.

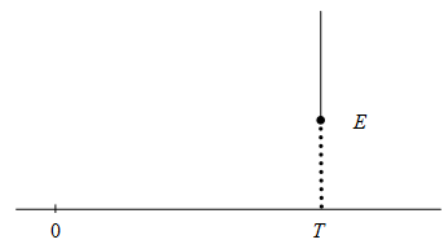

Fig2: A stochastic discount function.

Observe that $E \int_{E}^{+\infty} f(x) \mathrm{d} x$ aggregates all the cases in which $x>E$, that would make no sense in a discount function. On the other hand, observe that the stochastic discount function represents an amount with maturity at 0 , because $F(E)$ is a function of $S$, the price of the underlying asset at time 0 . Consequently, $F(E)$ denotes exclusively the stochastic component of the asset evolution from instant 0 to $T$, because the density function that appears in its expression, $f(x)$, is the density function of $X(T)$ conditioned by the price, $S$, of the underlying asset at time 0 . Finally, observe that, for the sake of simplicity, the variable $T$ has been removed from the expression of $F(E)$. Nevertheless, if necessary, we will write $F_{T}(E)$.

It could be demonstrated that $F(E)$ satisfies the conditions of a discount function (Cruz and Valls, 2008). Do we can 
state the following

Theorem 1. The function $F(E)=E \int_{E}^{+\infty} f(x) \mathrm{d} x+\int_{0}^{E} x f(x) \mathrm{d} x$, defined in the range of the random variable $X(T)$, satisfies the conditions to be a discount function, unless the monotonicity with respect to time, being not homogeneous of degree one with regard to the amount.

In this section, we are going to deduce some alternative expressions of the discount function using the price of call and put options.

\subsection{Discount function according to $P$}

In effect, adding and subtracting the expression $E \int_{0}^{E} f(x) \mathrm{d} x$ from the mathematical expression defining $F(E)$, we will successively have:

$$
\begin{aligned}
& F(E)=E \int_{E}^{+\infty} f(x) \mathrm{d} x+E \int_{0}^{E} f(x) \mathrm{d} x-E \int_{0}^{E} f(x) \mathrm{d} x+\int_{0}^{E} x f(x) \mathrm{d} x, \\
& F(E)=E \int_{0}^{+\infty} f(x) \mathrm{d} x-\int_{0}^{E}(E-x) f(x) \mathrm{d} x, \\
& F(E)=E-\int_{0}^{E}(E-x) f(x) \mathrm{d} x, \\
& F(E)=E-P(1+i)^{T},
\end{aligned}
$$

where $P=(1+i)^{-T} \int_{0}^{E}(E-x) f(x) \mathrm{d} x$ is the price of a put option (León and Serna, 2004: 33-49). Thus, taking into account this expression of the discount function depending on the price of the put option, we can state the following

Theorem 2. The price of a put option increases with respect to time if and only if

$$
\frac{\partial \ln D_{T}(E)}{\partial T}>\ln (1+i)
$$

being $D_{T}(E)=E-F_{T}(E)$ the discount magnitude corresponding to $F_{T}(E)$.

Proof. From the expression of the put option according to $F(E)$ :

$$
P=\left[E-F_{T}(E)\right](1+i)^{-T} \text {, }
$$

its derivative with respect to the time is:

$$
\frac{\partial P}{\partial T}=-\frac{\partial F_{T}(E)}{\partial T}(1+i)^{-T}+\left[E-F_{T}(E)\right](1+i)^{-T} \ln (1+i)(-1) \text {. }
$$

Therefore, the partial derivative is positive:

$$
\frac{\partial P}{\partial T}>0
$$

provided that it satisfies the following chain of equivalent inequalities:

$$
\begin{aligned}
& -\frac{\partial F_{T}(E)}{\partial T}>\left[E-F_{T}(E)\right] \ln (1+i), \\
& \frac{\frac{\partial D_{T}(E)}{\partial T}}{D(E)}>\ln (1+i), \\
& \frac{\partial \ln D_{T}(E)}{\partial T}>\ln (1+i) .
\end{aligned}
$$

Corollary 1. If the price of a put option is increasing with regard to time, then $F(E)$ is increasing with respect to $T$.

Proof. In effect, if $\frac{\partial P}{\partial T}>0$, by Theorem 2, one has:

$$
\frac{\partial F_{T}(E)}{\partial T}=-\frac{\partial D_{T}(E)}{\partial T}<-D_{T}(E) \ln (1+i)<0
$$


and the following inequality holds:

$\frac{\partial \ln D_{T}(E)}{\partial T}>\ln (1+i)$.

Nevertheless, in general, the converse implication is not true.

\subsection{Discount function according to $C$.}

An alternative expression of the discount function can be derived by using the price of a call option. In effect, starting from the put-call parity:

$(P-C)(1+i)^{T}=E-S(1+i)^{T}$,

one has:

$$
F(E)=(S-C)(1+i)^{T} \text {. }
$$

Recall that $C=(1+i)^{-T} \int_{E}^{+\infty}(x-E) f(x) \mathrm{d} x$ is obviously greater than 0 (boundary condition $\mathrm{C}_{1}$ ) and that if $E_{1}<E_{2}$ then $C_{1}>C_{2}$ (boundary condition $C_{4}$ ). On the other hand, taking into account the put-call parity, one has:

$$
P=C+E(1+i)^{-T}-S \geq E(1+i)^{-T}-S,
$$

from where $P \geq E(1+i)^{-T}-S$ (boundary condition $P_{2}$ ).

Finally, we can consider the discount magnitude, $D(E)=E-F(E)$, from two points of view:

Using the price of a call option:

$D(E)=E-(S-C)(1+i)^{T}$.

Using the price of a put option, in whose case:

$$
D(E)=P(1+i)^{T} \text {. }
$$

Figure 3 schematically summarizes the relationship between the price of the financial (call and put) options and the stochastic discount function defined at the beginning of Section 4:

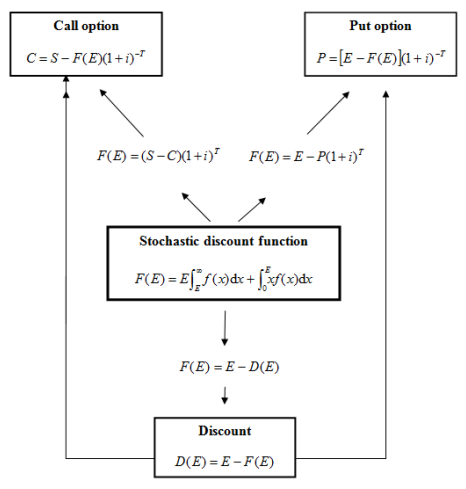

Fig 3: Relationship between the prices of the financial options and the discounting.

\subsection{Deriving the boundary conditions of call and put option prices.}

Once determined the relationship between the discount function, $F(E)$, and the financial option prices, $C$ and $P$, will use the usual discount properties of the function $F(E)$ to deduce the boundary conditions of $C$ and $P$. In this way, taking into account that the discount has two expressions, one for each class of option, we are going to obtain two set of boundary conditions: one for call options and another one for put options. Next, let us see each of them:

1. The discount has to be greater than or equal to 0 . Consequently, using the expression of the discount according to $P$, one has:

$$
D(E) \geq 0 \text {, }
$$




$$
\begin{aligned}
& P(1+i)^{T} \geq 0, \\
& P \geq 0 .
\end{aligned}
$$

Using the expression of the discount according to $C$, we obtain the corresponding boundary condition of the call option price:

$$
\begin{aligned}
& E-(S-C)(1+i)^{T} \geq 0, \\
& C \geq S-E(1+i)^{-T} .
\end{aligned}
$$

2. The discount cannot be greater than the amount to be discounted:

$$
\begin{aligned}
& D(E) \leq E, \\
& P(1+i)^{T} \leq E, \\
& P \leq E(1+i)^{-T} .
\end{aligned}
$$

Based on the expression using the put option price, it results in:

$$
\begin{aligned}
& E-(S-C)(1+i)^{-T} \leq E, \\
& S-C \geq 0, \\
& S \geq C .
\end{aligned}
$$

3. If $E_{1}<E_{2}$, then $D\left(E_{1}\right) \leq D\left(E_{2}\right)$ and therefore:

$$
\begin{aligned}
& P_{1}(1+i)^{T} \leq P_{2}(1+i)^{T}, \\
& P_{1} \leq P_{2} .
\end{aligned}
$$

Using the expression of the discount with respect to $C$ :

$$
\begin{aligned}
& E_{1}-\left(S-C_{1}\right)(1+i)^{T} \leq E_{2}-\left(S-C_{2}\right)(1+i)^{T}, \\
& \left(E_{2}-E_{1}\right)(1+i)^{-T} \geq C_{1}-C_{2} .
\end{aligned}
$$

Additionally and within this condition, we can consider the subtraction $D\left(E_{2}\right)-D\left(E_{1}\right)>0$ by simultaneously using the two expressions of the discount according to $C$ and $P$, resulting in:

$$
\begin{aligned}
& {\left[E_{2}-\left(S-C_{2}\right)\left(1+i^{T}\right)\right]-\left[E_{1}-\left(S-C_{1}\right)(1+i)^{T}\right]=P_{2}(1+i)^{T}-P_{1}(1+i)^{T},} \\
& \left(E_{2}-E_{1}\right)+\left(C_{2}-C_{1}\right)(1+i)^{T}=P_{2}(1+i)^{T}-P_{1}(1+i)^{T} .
\end{aligned}
$$

Multiplying both sides of last equality by $(1+i)^{-T}$, one has:

$$
\left(E_{2}-E_{1}\right)(1+i)^{-T}+\left(C_{2}-C_{1}\right)=P_{2}-P_{1} \text {. }
$$

If $C_{1}>C_{2}$, it can be deduced that:

$$
\left(E_{2}-E_{1}\right)(1+i)^{-T}+\left(C_{2}-C_{1}\right) \leq\left(E_{2}-E_{1}\right)(1+i)^{-T},
$$

and therefore

$$
P_{2}-P_{1} \leq\left(E_{2}-E_{1}\right)(1+i)^{-T} \text {. }
$$

4. If $T_{1}<T_{2}$, then $D\left(T_{1}\right) \leq D\left(T_{2}\right)$ and therefore, considering the discount according to $P$, one has:

$$
P_{1}(1+i)^{T_{1}} \leq P_{2}(1+i)^{T_{2}} \text {, }
$$

where anything can be deduced about a possible relationship between $P_{1}$ and $P_{2}$, unless we propose additional conditions to the stochastic process defining the behavior of $X(T)$. In order to analyze this relationship in depth, we have consulted several references where different hypotheses have been proposed to relate the price of financial options to time.

In Hull (1989), the relationship between the variation of the option price and the variation of the expiration date is studied. More specifically, this ratio is the well-known theta, $\Theta$, which represents the sensitivity, ceteris paribus, of the put option price with respect to changes in time:

$$
\Theta=\frac{\partial P}{\partial T} \text {. }
$$

Hull states that theta has a negative value since the price of a put option diminishes $(\nabla P)$ as time increases $(\Delta T)$. This is because of the reduced risk of the option when its maturity becomes closer. However and from a mathematical point of view, this statement cannot be supported (see Example 1).

Finally, we can obtain the boundary condition corresponding to the call option price: 


$$
\begin{aligned}
& E-\left(S-C_{1}\right)(1+i)^{T_{1}} \leq E-\left(S-C_{2}\right)(1+i)^{T_{2}}, \\
& \left(S-C_{1}\right)(1+i)^{T_{1}} \geq\left(S-C_{2}\right)(1+i)^{T_{2}}>\left(S-C_{2}\right)(1+i)^{T_{1}}, \\
& C_{2} \geq C_{1} .
\end{aligned}
$$

Moreover, we can state the following

Theorem 3. The function $F(E)$ is strictly decreasing with respect to $T$ if and only if the price of the call option is strictly increasing with respect to time.

The following example shows that the partial derivate with respect to time of the price of a call option is greater than zero (which leads to a discount function strictly decreasing with respect to $T$ ). Nevertheless, the partial derivative of the corresponding put option can be positive, negative or zero (Lamothe, 1993: 145).

Example 1. Assume that the price of the underlying asset follows, as in Black-Scholes' model (1973), a log-normal distribution. It is well-known that the log-normal distribution has, in general, the following density function:

$$
f(x)=\frac{1}{x \sigma \sqrt{2 \pi}} e^{-\frac{(\ln x-\mu)^{2}}{2 \sigma^{2}}},
$$

with mean $e^{\mu+\frac{\sigma^{2}}{2}}$ and standard deviation $\left(e^{\sigma^{2}}-1\right) e^{2 \mu+\sigma^{2}}$.

In Black-Scholes model the natural logarithm of the underlying asset price, $\ln S_{T}$, follows a normal distribution, with mean $\ln S_{0}+\left(\mu-\frac{\sigma^{2}}{2}\right) T$ and variance $\sigma^{2} T$ (Dinnen, 2013). On the other hand, the density function of the underlying asset is the following:

$$
f_{T}(x)=\frac{1}{x \sigma \sqrt{T} \sqrt{2 \pi}} e^{-\frac{\left(\ln x-\ln S_{0}-\mu T+\frac{\sigma^{2}}{2} T\right)^{2}}{2 \sigma^{2} T}} .
$$

In this case, the call option price is:

$C=S \cdot F\left(d_{1}\right)-E \cdot e^{-r T} \cdot F\left(d_{2}\right)$,

where $d_{1}=\frac{\ln \frac{S}{E}+\left(r+\frac{1}{2} \sigma^{2}\right) T}{\sigma \sqrt{T}}$ and $d_{2}=d_{1}-\sigma \sqrt{T}$. On the other hand, the put option price is:

$P=C-S+E \cdot e^{-r T}$.

Now, it can be demonstrated that:

$$
\frac{\partial C}{\partial T}=S \cdot f\left(d_{1}\right) \cdot \frac{\sigma}{2 \sqrt{T}}-E \cdot e^{-r T} \cdot r \cdot F\left(d_{2}\right)>0,
$$

from which, based on Theorem 3, it can stated that $\frac{\partial F_{T}(E)}{\partial T}<0$. Whereas:

$$
\frac{\partial P}{\partial T}=\frac{\partial C}{\partial T}-E \cdot e^{-r T} \cdot r,
$$

whose value can positive, negative or even zero.

As a result, if the put-call parity holds, we can summarize the former results in Table 1.

Table 1: Implications between the signs of the discount function and the call and put options.

\begin{tabular}{|l|c|c|}
\hline Call option & $\frac{\partial C}{\partial T}>0$ (Theorem 3) & $\frac{\partial C}{\partial T} \leq 0$ \\
\hline Discount function & $\frac{\partial F_{T}(E)}{\partial T}>0$ & $\frac{\partial F_{T}(E)}{\partial T} \leq 0$ \\
\hline Put option & $\frac{\partial P}{\partial T}>0$ (Theorem 2) & $\frac{\partial P}{\partial T} \leq 0$ \\
\hline
\end{tabular}


5. As the discount magnitude is a convex function of the amount to be discounted:

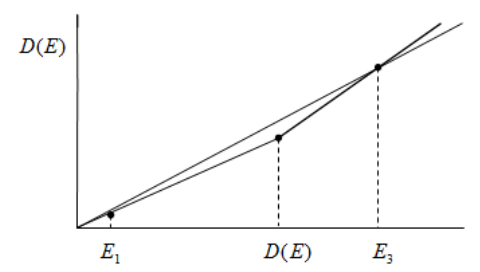

Fig 4: Discount function with respect to $E$.

The slope of the segment from $\left(E_{1}, D\left(E_{1}\right)\right)$ to $\left(E_{2}, D\left(E_{2}\right)\right)$ is lower than the slope of the segment from $\left(E_{2}, D\left(E_{2}\right)\right)$ to $\left(E_{3}, D\left(E_{3}\right)\right)$. Said in other words,

$$
\frac{D\left(E_{2}\right)-D\left(E_{1}\right)}{E_{2}-E_{1}}<\frac{D\left(E_{3}\right)-D\left(E_{2}\right)}{E_{3}-E_{2}} .
$$

Substituting the discount according to the put price and simplifying the capitalization factor $(1+i)^{T}$, one has:

$$
\frac{P_{2}-P_{1}}{E_{2}-E_{1}}<\frac{P_{3}-P_{2}}{E_{3}-E_{2}} \text {. }
$$

Thus, it can be obtained that:

$$
P_{2}<\frac{E_{3}-E_{2}}{E_{3}-E_{1}} P_{1}+\frac{E_{2}-E_{1}}{E_{3}-E_{1}} P_{3} \text {. }
$$

To derive the corresponding call option boundary condition, we follow a similar procedure, remaining:

$$
\begin{aligned}
& \frac{E_{2}-\left(S-C_{2}\right)(1+i)^{T}-\left[E_{1}-\left(S-C_{1}\right)(1+i)^{T}\right]}{E_{2}-E_{1}}< \\
& <\frac{E_{3}-\left(S-C_{3}\right)(1+i)^{T}-\left[E_{2}-\left(S-C_{2}\right)(1+i)^{T}\right]}{E_{3}-E_{2}},
\end{aligned}
$$

from where:

$$
\begin{aligned}
& C_{2}>-E_{2}(1+i)^{-T} \frac{E_{3}-E_{2}}{E_{3}-E_{1}}-E_{2}(1+i)^{-T} \frac{E_{2}-E_{1}}{E_{3}-E_{1}}+E_{1}(1+i)^{-T} \frac{E_{3}-E_{2}}{E_{3}-E_{1}}+ \\
& +E_{3}(1+i)^{-T} \frac{E_{2}-E_{1}}{E_{3}-E_{1}}+C_{3} \frac{E_{2}-E_{1}}{E_{3}-E_{1}}+C_{1} \frac{E_{3}-E_{2}}{E_{3}-E_{1}} .
\end{aligned}
$$

As

$$
\begin{aligned}
& -E_{2}(1+i)^{-T} \frac{E_{3}-E_{2}}{E_{3}-E_{1}}-E_{2}(1+i)^{-T} \frac{E_{2}-E_{1}}{E_{3}-E_{1}}+E_{1}(1+i)^{-T} \frac{E_{3}-E_{2}}{E_{3}-E_{1}}+ \\
& +E_{3}(1+i)^{-T} \frac{E_{2}-E_{1}}{E_{3}-E_{1}}=0,
\end{aligned}
$$

one has:

$$
C_{2}<C_{1} \frac{E_{3}-E_{2}}{E_{3}-E_{1}}+C_{3} \frac{E_{2}-E_{1}}{E_{3}-E_{1}} .
$$

The aforementioned results can be summarized in Table 2 . 
Table 2: Boundary conditions of call and put option prices from the discount properties.

\begin{tabular}{|c|c|c|c|}
\hline Discount properties & $D_{i j}$ & Call boundary conditions & Put boundary conditions \\
\hline \multirow{2}{*}{$\begin{array}{l}\text { Condition } \mathbf{D}_{1} \\
D(E) \geq 0\end{array}$} & $\mathrm{D}_{11}$ & $\left(^{*}\right)$ & $\begin{array}{c}\text { Condition } P_{1} \\
P \geq 0\end{array}$ \\
\hline & $D_{12}$ & $\begin{array}{c}\text { Condition } \mathbf{C}_{2} \\
C \geq S-E(1+i)^{-T}\end{array}$ & $\left({ }^{* *}\right)$ \\
\hline \multirow{2}{*}{$\begin{array}{l}\text { Condition } \mathbf{D}_{2} \\
D(E) \leq E\end{array}$} & $\mathrm{D}_{21}$ & - & $\begin{array}{c}\text { Condition } \mathbf{P}_{3} \\
P \leq E(1+i)^{-T}\end{array}$ \\
\hline & $\mathrm{D}_{22}$ & $\begin{array}{c}\text { Condition } \mathrm{C}_{3} \\
\quad S \geq C\end{array}$ & 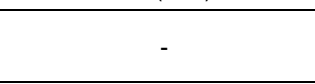 \\
\hline \multirow{2}{*}{$\begin{array}{l}\text { Condition } \mathrm{D}_{3} \\
D\left(E_{1}\right) \leq D\left(E_{2}\right) \\
\text { being } E_{1}<E_{2}\end{array}$} & $D_{31}$ & $\left({ }^{* \star *}\right)$ & $\begin{array}{c}\text { Condition } \mathbf{P}_{4} \\
P_{1} \leq P_{2}\end{array}$ \\
\hline & $\mathrm{D}_{32}$ & $\begin{array}{c}\text { Condition } \mathbf{C}_{5} \\
\left(E_{2}-E_{1}\right)(1+i)^{-T} \geq C_{1}-C_{2}\end{array}$ & $\begin{array}{c}\text { Condition } \mathbf{P}_{5} \\
P_{2}-P_{1} \leq\left(E_{2}-E_{1}\right)(1+i)^{-T}\end{array}$ \\
\hline \multirow{2}{*}{$\begin{array}{l}\text { Condition } \mathrm{D}_{4} \\
D\left(E_{1}\right) \leq D\left(E_{2}\right) \\
\text { being } T_{1}<T_{2}\end{array}$} & $\mathrm{D}_{41}$ & 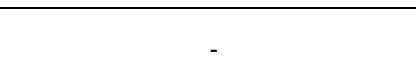 & $\begin{array}{c}\text { Condition } \mathbf{P}_{6} \\
P_{1} \leq P_{2} ?\end{array}$ \\
\hline & $\mathrm{D}_{42}$ & $\begin{array}{c}\text { Condition } \mathbf{C}_{6} \\
C_{1} \leq C_{2}\end{array}$ & 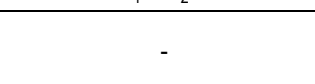 \\
\hline \multirow{2}{*}{$\begin{array}{c}\text { Condition } \mathbf{D}_{5} \\
\frac{D\left(E_{2}\right)-D\left(E_{1}\right)}{E_{2}-E_{1}} \leq \frac{D\left(E_{3}\right)-D\left(E_{2}\right)}{E_{3}-E_{2}}\end{array}$} & $D_{51}$ & - & $\begin{array}{c}\text { Condition } \mathbf{P}_{7} \\
P_{2} \leq \frac{E_{3}-E_{2}}{E_{3}-E_{1}} P_{1}+\frac{E_{2}-E_{1}}{E_{3}-E_{1}} P_{3}\end{array}$ \\
\hline & $\mathrm{D}_{52}$ & Condition $C_{7} \quad C_{2} \leq C_{3} \frac{E_{2}-E_{1}}{E_{3}-E_{1}}-C_{1} \frac{E_{3}-E_{2}}{E_{3}-E_{1}}$ & ( \\
\hline
\end{tabular}

The following boundary conditions have been obtained directly from the two versions of the definition of $F(E)$ :

$\left(^{*}\right) C=(1+i)^{-T} \int_{E}^{+\infty}(x-E) f(x) \mathrm{d} x$ is obviously greater than 0 (condition $\mathbf{C}_{1}$ ).

$\left.{ }^{* *}\right) P \geq E(1+i)^{-T}-S$ (condition $\mathbf{P}_{2}$ ).

$\left.{ }^{* * *}\right)$ If $E_{1} \leq E_{2}$ then $C_{1}>C_{2}$ (condition $C_{4}$ ).

$\mathrm{D}_{i j}$ represents the discount properties. The first subscript, $i$, indicates the discount condition $(1,2,3,4$ or 5$)$ used to derive the options boundary conditions. Whereas the second subscript, $j$, takes the values 1 or 2 , depending on the version used for the discount condition. Thus,

- $j=1$ means that the put option price has been employed to calculate the discount:

$$
D(E)=P(1+i)^{T} .
$$

- $\quad j=2$ implies that the discount has been obtained from the call option price:

$D(E)=E-(S-C)(1+i)^{T}$.

\section{Conclusion}

Traditionally, the concept of a financial (call or put) option has been studied independently of the concept of discount. In effect, whereas the first concept belongs to the field of assets risk, the second one is characteristic of the classical Financial Mathematics. Nevertheless, in this paper these two concepts have been jointly analyzed and related between them.

Thus, the main contribution of this work is the introduction of a stochastic discount function in whose expression either the call or the put option price is involved. As a consequence, the corresponding discount magnitude is a function of the aforementioned prices, whereby the boundary conditions for both call and put options prices can be derived from the discount properties and vice versa.

The approach used to reach this objective has been to start from a stochastic discount function whose defining expression is firstly based on the price of a put option. This has allowed us to obtain the put boundary conditions from the 
corresponding discount properties. Analogously, we have obtained the dual boundary conditions for call options based on the put-call parity expression. This methodology has been useful for all conditions except for the increase of the put option price with respect to its maturity. In this way, we have provided some references dealing with this issue. In any case, Theorem 2 relates the increase of the put option price to the decrease of the so-defined stochastic discount function both with respect to time. Furthermore, Theorem 3 shows that the stochastic discount function is decreasing if and only if the call option price is increasing both with respect to time.

Table 2 summarizes the correspondence between the boundary conditions of both call and put option price, and the financial discount. Nevertheless, the discount function used in this work is not the only one that can be defined for this aim. So we leave for future research considering other discount functions and deriving some possible additional boundary conditions of options depending on the particular family of probability distributions describing the behavior of random price of the underlying asset.

\section{References}

Björk, T. (2009). Arbitrage theory in continuous time. Oxford University Press.

Björk, T., and Slinko, I. (2006). Towards a general theory of good-deal bounds. Review of Finance, 10, 2, 221-260.

Black, F., \& Scholes, M. (1973). The pricing of options and corporate liabilities. Journal of Political Economy, 81 (3), 637-654.

Chua, A., DeLisle, R. J., Feng, S. S., \& Lee, B. S. (2015). Price-to-earnings ratios and option prices. Journal of Futures Markets, 35(8), 738-752.

Cochrane, J.H. (2009). Asset Pricing: (Revised Edition). Princeton University Press.

Cox, J.C., \& Rubinstein, M. (1985). Option markets. New York: Prentice Hall, Englewood Cliffs.

Cruz Rambaud, S., \& Trinidad Segovia, J.E. (2004). The properties of options from stochastic discounting functions. Proceedings of the 35th Meeting of the EWGFM, 14 y 15 de octubre, Almería.

Cruz Rambaud, S., Valls Martínez, M.C., \& García García, C.B. (2002). Financial laws associated with continuous stochastic processes. Proceedings of the $V$ Congreso de Matemática Financiera y Actuarial and 5th Italian-Spanish Conference on Financial Mathematics, 20-26 de junio, Valencia.

Cruz Rambaud, S., \& Valls Martínez, M.C. (2008). Introducción a las matemáticas financieras (Introduction to financial mathematics). Madrid: Pirámide.

Devolder, P. (1997). Un tour du monde des options (A tour to the options world). IV Congreso Matemática de las Operaciones Financieras, 26, 27 y 28 de noviembre, Barcelona.

Díez de Castro, L., \& Mascareñas Pérez-lñigo, J. (1994). Ingeniería financiera. La gestión en los mercados financieros internacionales (Financial engineering. The international markets management). Madrid: McGraw-Hill.

Dinnen, S., (2013). Probability theory in finance: A mathematical guide to the Black-Scholes formula (2nd Edition). Graduate Studies in Mathematics, vol. 70. American Mathematical Society. USA.

Galai, D. (1978). Empirical tests of boundary conditions for CBOE options. Journal of Political Economy, 6, 187-211.

Galai, D. (1983). A survey of empirical tests of option pricing models. In M. Brenner (Ed.) Option Pricing. Lexington: Lexington Books, Mass.: (pp. 45-80).

González Catalá, V.T. (1992). Análisis de las operaciones financieras, bancarias y bursátiles. Ediciones de las Ciencias Sociales, Madrid.

Gould, J., \& Galai, D. (1974): Transaction costs and the relationship between put and call prices. Journal of Financial Economics, 1, 105129.

Hong, Y. (2013). Valuation bounds on barrier options under model uncertainty. Journal of Futures Markets, 33(3), 199-234.

Hull, J.C. (1989). Options, futures, and other derivatives. (3th ed.). New Jersey: Prentice-Hall.

Jahnke, H., Martini, J. T., \& Wiens, T. (2015). Price limits under incomplete preference information based on almost stochastic dominance. Available at SSRN 1320203.

Jarrow, R., \& Rudd, A. (1983). Option pricing. Richard Irwin Inc., Homewood, III.

Kalay, A., Karakaş, O., \& Pant, S. (2014). The market value of corporate votes: Theory and evidence from option prices. The Journal of Finance, 69(3), 1235-1271.

Klemkosky, R., \& Resnick, B. (1979). Put call parity and market efficiency. Journal of Financial Economics, 34, 1141-1155.

Kunsch, P.L., Ruttiens, A., \& Chevalier, A. (2008). A methodology using option pricing to determine a suitable discount rate in environmental management. European Journal of Operational Research, 185, 1674-1679.

Lamothe, P. (1993). Opciones financieras. Un enfoque fundamental (Financial Opcions. A fundamental approach). McGraw-Hill: Madrid.

Lamothe, P., Pérez Somalo, M. (2003). Opciones financieras y productos estructurados (Financial options and structured products). (2nd ed.). Madrid: McGraw-Hill.

León Valle, A., \& Serna Calvo, G. (2004). Modelos alternativos de valoración de opciones sobre acciones: una aplicación al mercado español (Alternative models of valuation of options on shares: an application to the Spanish market). Cuadernos Económicos de ICE, 69, 33-49.

Levy, H. (1985). Upper and lower bounds of put and call option value: stochastic dominance approach. Journal of Finance, 40, 11971217. 
Liu, Y., Chen, X., \& Ralescu, D. A. (2015). Uncertain currency model and currency option pricing. International Journal of Intelligent Systems, 30(1), 40-51.

Merton, R. (1973). Theory of rational option pricing. Bell Journal of Economics and Management Science, 4, 141-184.

Murgoci, A. (2013). Vulnerable derivatives and good deal bounds: a structural model. Applied Mathematical Finance, 20(3), $246-263$.

Oancea, I. M., \& Perrakis, S. (2014). From stochastic dominance to Black-Scholes: An alternative option pricing paradigm. Risk and Decision Analysis, 5(2-3), 99-112.

Perrakis, S., \& Ryan, P. (1984). Option pricing bounds in discrete time. Journal of Finance, 39, 519-525.

Ritchken, P. (1985). On option pricing bounds. Journal of Finance, 40, 1219-1233.

Ritchken, P., \& Kuo, S. (1988). Option pricing bounds with finite revision opportunities. Journal of Finance, 43, 301-308.

Stoll, H. (1969). The Relationship between put and call option prices. Journal of Finance, 31, 319-332.

Vorst, T. (1990). Option Pricing and Stochastic. In F. van Der Ploeg (Ed.) Advanced Lectures in Quantitative Economics. London: Academic Press Limited. 